\title{
Up-pulling force analysis for ESC hollow cylindrical casting
}

\author{
*An-guo Wang ${ }^{1,2}$, Zhou-hua Jiang1, Yan-chun Lou², Ji Tang ${ }^{2}$, Yun-long Xiong ${ }^{2}$, Yan-wu Dong', Yan-wu Dong', \\ Fu-bin Liu', Jing-chang Cheng ${ }^{2}$ and Rui Chen ${ }^{2}$ \\ 1. Northeastern University, Shenyang 110819, China \\ 2. Shenyang Research Institute of Foundry, Shenyang 110022, China
}

\begin{abstract}
Electroslag casting (ESC) is an important method to produce high quality castings. In this study, the ESC up-pulling inner mold method (EUPIM) was used to produce hollow cylindrical castings with the multiple consumable electrodes. The radial deformation, the axial and radial internal stress of the inner mold, and the axial internal stress of the slag shell were analyzed using the finite element method (FEM) with the aid of ANSYS software. The ProCAST software was used to calculate the specific heat, heat conductivity and density curve of $\mathrm{Cu}$. Simulation results show that the radial deformation, the axial and radial internal stress of the inner mold, and the axial internal stress of the slag shell near the slag-metal interface of hollow cylndrical casting gradually increase from $0 \mathrm{~s}$ to $360 \mathrm{~s}$ after the ESC starting (slagging) process but before applying the up-pulling force. The suitable initial up-pulling moment of the inner mold is at around 180-198 s after the starting process.
\end{abstract}

Key words: ESC; up-pulling; EUPIM; hollow cylindrical casting; FEM; internal stress; sustainability
CLC numbers: TG142
Document code: $\mathrm{A}$
Article ID: 1672-6421(2020)01-048-08

$\mathrm{W}$ ith the upgrading of major equipment for nuclear power and thermal power, the demand for high quality large-sized hollow cylindrical and special-shaped castings is increasing. Compared with the forging process, electroslag casting (ESC) is a more economical and reasonable way to produce high quality hollow cylindrical and special-shaped casting ${ }^{[1-3]}$. A hollow cylindrical casting can be produced by pulling down the casting during the ESC process (ESC extraction method). However, hollow special-shaped (with variable cross sections) castings cannot be produced by ESC extraction method due to the hindrance of the outer mold. The hollow specialshaped castings can be produced by rising the inner mold through a bottom water-tank during the ESC process (ESC hot piercing method); however, the inner mold can be easily damaged by prolonged high temperature. Furthermore, many ESC furnaces are not equipped with an elevating device for a water cooling bottom plate, so, ESC extraction method and ESC hot piercing method cannot be implemented. To overcome these shortages in

\section{*An-guo Wang}

Male, born in 1979, Ph.D, Senior Engineer. His research interests mainly focus on the process design and numerical simulation of the ESC process and other solidification processes.

E-mail: 315097641@qq.com

Corresponding author: Yan-wu Dong

E-mail: dongyw@smm.neu.edu.cn

Received: 2018-01-02; Accepted: 2019-10-19 manufacturing hollow special-shaped casting, the ESC uppulling inner mold method (EUPIM) was developed.

In this study, EUPIM experiment was designed to produce the ESC CF3 hollow cylindrical casting. Since the unsuitable initial up-pulling moment can lead to failure of EUPIM (inner mold copper plate stuck with casting or slag leakage), a combination of numerical simulation and experimental research was adopted to confirm the suitable initial up-pulling moment of EUPIM after the ESC starting (i.e. slagging) process. The finite element method (FEM) and mathematical model were used for numerical simulation.

\section{Experimental procedure}

\subsection{Experimental preparation}

The ESC up-pulling linkage control equipment for an ESC hollow cylindrical casting was designed, as shown in Fig. 1(a), which was used for lifting the inner mold. The inner diameter of the outer mold was $\Phi 550 \mathrm{~mm}$, and the outer diameter of the inner mold was $\Phi 220 \mathrm{~mm}$. The working surfaces of the inner and outer molds were made of rolled pure copper plate. The ESC up-pulling linkage control equipment together with the inner mold was pulled up along the slag shell. A sensor was used to send signals to the up-pulling linkage control equipment. The concentricity of the inner mold and outer mold was guaranteed by the guide bar. The residual stress of the 
(a)

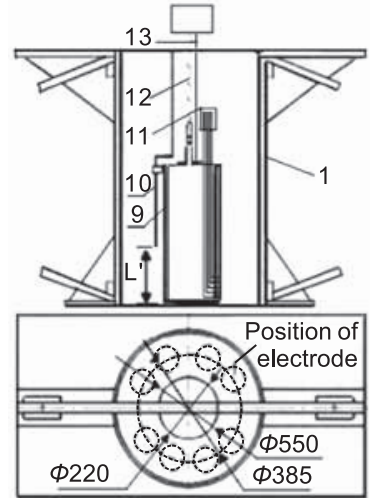

(b)

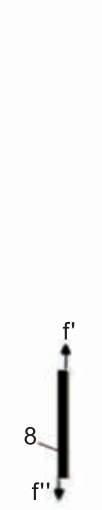

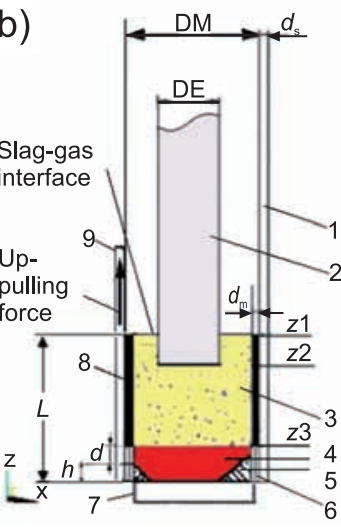

(c)

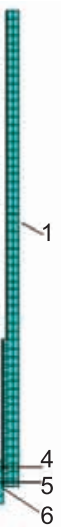

1. Outer mold; 2. Consumable electrode; 3. Slag pool; 4. Metal basin; 5. Solidified casting; 6. Gas gap, 7. Bottom water tank; 8. Slag shell; 9. Inner mold; 10. Sensor; 11. Residual stress test instrument; 12. Up-pulling linkage control equipment; 13. Guide bar

Fig. 1: (a) EUPIM equipment; (b) Schematic of the initial up-pulling process; (c) 3D model for ESC hollow casting

inner mold copper plate without the ESC up-pulling force was measured by a residual stress test instrument.

The consumable electrodes were designed considering the composition and shape of the hollow cylindrical ESC CF3 casting. The material of the consumable electrodes is CF3 (ASTM A351), and its compositions are shown in Table 1. The electrode is columnar with a diameter of $70 \mathrm{~mm}$. Eight (8) electrodes were used which uniformly distributed in a radial direction (Fig. 2) between the inner and the outer molds.

\section{Table 1: Compositions of $\mathrm{CF} 3$ consumable electrodes for ESC hollow casting (\%)}

\begin{tabular}{ccccccccc}
$\mathbf{C}$ & $\mathrm{Si}$ & $\mathrm{Mn}$ & $\mathbf{P}$ & $\mathbf{S}$ & $\mathbf{C r}$ & $\mathrm{Ni}$ & $\mathrm{Mo}$ & $\mathrm{Fe}$ \\
\hline 0.026 & 1.4 & 1.2 & 0.021 & 0.007 & 18.35 & 8.36 & 0.41 & Bal.
\end{tabular}

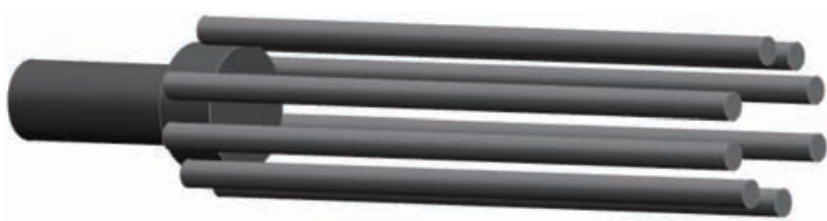

Fig. 2: Model of consumable electrodes for ESC hollow casting

\subsection{Importance of initial up-pulling moments for EUPIM}

In the up-pulling process of EUPIM, the distance from the sensor front-end to the inner mold bottom, $L^{\prime}$ (Fig. 1), and the distance from the slag-gas interface to the inner mold bottom, $L$, fluctuate in a small range. When the sensor initially monitors the slag-gas interface, $L^{\prime}$ equals to $L$, and the controller allows the up-pulling linkage control equipment to lift the inner mold up for a fixed distance " $l$ ". When the sensor monitors the slag-gas interface again with the suitable initial up-pulling moments, $L^{\prime}$ equals to " $L+l$ ", and the cycle continues from beginning to the end of the EUPIM process.

The suitable EUPIM initial up-pulling moment should satisfy the following conditions:

(1) The radial deformation of the inner mold copper plate does not prevent the radial shrinkage of the casting.

(2) Both the axial and radial internal stresses of the inner mold copper plate are less than the tensile strength of copper plate to avoid cracking of the copper plate.

(3) The axial internal stress of the inner mold copper plate is less than its yield strength to avoid the unrecoverable deformation of the copper plate.

(4) The slag shell is strong enough, and the axial internal stress does not exceed the tensile strength of the slag shell.

\subsection{FEM model and analysis}

The EUPIM process was analyzed with the aid of the FEM method. To simplify the FEM model for numerical simulation, the following basic assumptions are given ${ }^{[4-6]}$ :

(1) The EUPIM process is in a quasi-steady state;

(2) The slag/metal interface is a horizontal surface;

(3) The change of the ingot height is negligible during each EUPIM process;

(4) The heat transfer in the metal basin is taken into account as effective thermal conductivity;

(5) The established model is axial symmetry in the cylindrical coordinate system.

The ESC initial up-pulling schematic, and the 1/16 ESC initial up-pulling 3D model of the ESC hollow cylindrical castings are shown in Fig. 1 . The height of slag pool, $H_{\text {slag, }}$ was about $150 \mathrm{~mm}$, and the safety margin, $d$, was about $10 \mathrm{~mm}$. The FEM analysis of the initial up-pulling process was carried out with the thermo-elastic plastic incremental FEM model ${ }^{[7]}$ no matter whether the up-pulling force was applied or not.

In this study, the radial ( $R$ direction) deformation, the axial ( $Z$ direction or the direction of gravity) and radial internal stress of the inner mold copper plate, and the axial internal stress of the slag shell near the slag-metal interface and the base line (the slag-metal interface at $60 \mathrm{~s}$ after the starting process) were analyzed using the FEM method, before and after applying the ESC up-pulling force at $0-360 \mathrm{~s}$ after the starting process, which can help to determine the suitable initial up-pulling moments.

From the viewpoint of heat transfer, the ESC process is a quasi-steady heat conduction process with a moving heat 
source, and the internal stress of the inner mold copper plate changes with temperature. The FEM internal stress analysis of the inner mold and the slag shell was carried out with the aid of "ANSYS" commercial software. By using heat, elastic and plastic incremental finite element models, the transient axial and radial internal stresses of the ESC hollow cylindrical metal basin model (including mold copper plate, slag shell, melt basin and bottom water tank) were analyzed.

Heat conduction Eq. (1) and heat balance Eq. (2) ${ }^{[7,8]}$ were used to calculate the temperature of each region. Equation (3) ${ }^{[7,8]}$ shows the relationship among internal stress, elasticplastic matrix and elastic-plastic strain at a given temperature. Equations (4) and (5) show the principles of strain gauges (Fig. 3) for internal stress test instrument.

$$
\begin{gathered}
\rho C_{\mathrm{p}} \partial T / \partial \mathrm{t}=\nabla \cdot K_{\mathrm{eff}} \nabla T+S_{\mathrm{T}} \\
q=q_{\mathrm{mwi}}+q_{\mathrm{mwo}}+q_{\mathrm{mb}}+q_{\mathrm{se}}+q_{\mathrm{swi}}+q_{\mathrm{swo}}+q_{\mathrm{d}}+q_{\mathrm{r}}
\end{gathered}
$$

where, $\nabla$ is the Hamiltonian operator, dimensionless; $\rho$ is the density, $\mathrm{kg} / \mathrm{m}^{3} ; C_{\mathrm{p}}$ is the specific heat capacity, $\mathrm{J} / \mathrm{kg} / \mathrm{K} ; \partial$ is the derivative symbol, dimensionless; $T$ is the temperature of the study particle, $\mathrm{K} ; t$ is time, $\mathrm{s} ; K_{\text {eff }}$ is the effective thermal conductivity, $\mathrm{W} / \mathrm{m} / \mathrm{K} ; S_{\mathrm{T}}$ is the calorific density, $\mathrm{W} / \mathrm{m}^{3} ; q$ is the thermal power of system, $q_{\text {mwi }}, q_{\text {mwo }}, q_{\mathrm{mb}}, q_{\mathrm{se}}, q_{\mathrm{swi}}, q_{\mathrm{swo}}, q_{\mathrm{d}}$ and $q_{\mathrm{r}}$ are the heat exchange rates between the casting and the inner mold, the outer mold, the bottom water tank; the heat exchange rate between the slag pool and the electrode, the inner mold, the outer mold, the heat absorption rate of droplet, and the radial heat loss rate of slag pool, respectively, $\mathrm{W}$.

$$
d\{\sigma\}=\{D\}_{\mathrm{ep}}\left(d\left\{\varepsilon_{\mathrm{ep}}\right\}-d\left\{\varepsilon_{0}\right\}\right)
$$

where, $\sigma$ is stress, $\mathrm{N} \cdot \mathrm{m}^{-2} ;\{D\}_{\text {ep }}$ is elastic-plastic matrix, which changes with temperature, $\mathrm{N} \cdot \mathrm{m}^{-2} ; \varepsilon_{\text {ep }}$ is elastic-plastic strain, dimensionless; $\varepsilon_{0}$ is initial strain, dimensionless.

$$
\begin{gathered}
\sigma_{\max }, \sigma_{\min }=\frac{\varepsilon_{3}-\varepsilon_{1}}{4 \bar{A}} \pm \frac{\sqrt{\left(\varepsilon_{3}-\varepsilon_{1}\right)^{2}-\left(\varepsilon_{3}+\varepsilon_{1}-2 \varepsilon_{2}\right)^{2}}}{4 \bar{B}} \\
\beta=\frac{1}{2} \arctan \left(\frac{\varepsilon_{3}+\varepsilon_{1}-2 \varepsilon_{2}}{\varepsilon_{3}-\varepsilon_{1}}\right)
\end{gathered}
$$

where $\sigma_{\max }$ and $\sigma_{\min }$ are the maximum and minimum principal stresses, $\mathrm{Pa} ; \varepsilon_{1}, \varepsilon_{2}, \varepsilon_{3}$ are the measured strains at Gauges 1, 2, 3; $A, B$ are the constants (decide on material and rosette shape of strain gauges); $\beta$ is the angle between the measured principal stress and Gauge 1. The axial and the radial internal stresses of the inner mold at $60 \mathrm{~s}, 180 \mathrm{~s}, 300 \mathrm{~s}$ after the ESC starting process were measured.

At the different ESC initial up-pulling moments, i.e., 60-78 s $\left(\tau_{1}\right), 180-198 \mathrm{~s}\left(\tau_{2}\right)$ and $300-318 \mathrm{~s}\left(\tau_{3}\right)$ after the ESC starting process, the reliability of FEM analysis on internal stress could be verified with the aid of strain gauges (Fig. 3).

In the simulation, the applied electric power is about $62 \mathrm{~V} \times 10000 \mathrm{~A}$; the remelting speed is about $1.67 \times 10^{-4} \mathrm{~m} / \mathrm{s}$; the heat convection coefficient between the water and the inner mold

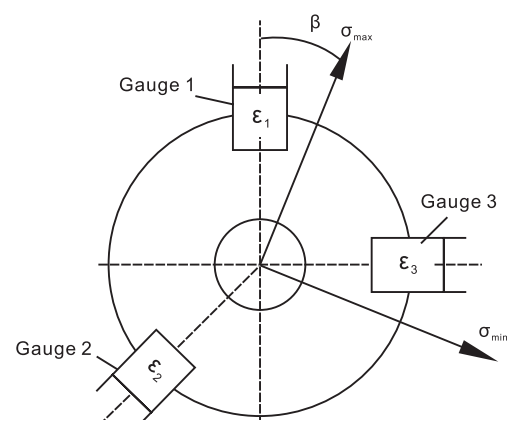

Fig. 3: Strain gauges for internal stress test

$\left(\alpha_{\text {inner }}\right)$ is $1,378 \mathrm{~W} / \mathrm{m}^{2} / \mathrm{K}$, between the water and the outer mold $\left(\alpha_{\text {outer }}\right)$ is $1,368 \mathrm{~W} / \mathrm{m}^{2} / \mathrm{K}$, and between the water and the bottom water tank is $600 \mathrm{~W} / \mathrm{m}^{2} / \mathrm{K}$. The liquid slag, the once slag shell (solidified slag shell between slag pool and mold) and twice slag shell (solidified slag shell remelted by metal basin) are modified ANF-6 (70\% $\mathrm{CaF}_{2}$ and $\left.30 \% \mathrm{Al}_{2} \mathrm{O}_{3}\right)$. ProCAST software was used to calculate the specific heat, heat conductivity and density curve of $\mathrm{Cu}$, as shown in Fig. 4, and the specific enthalpy, thermal conductivity and density curve of CF3, as shown in Fig. 5. Other parameters are listed in Table 2.

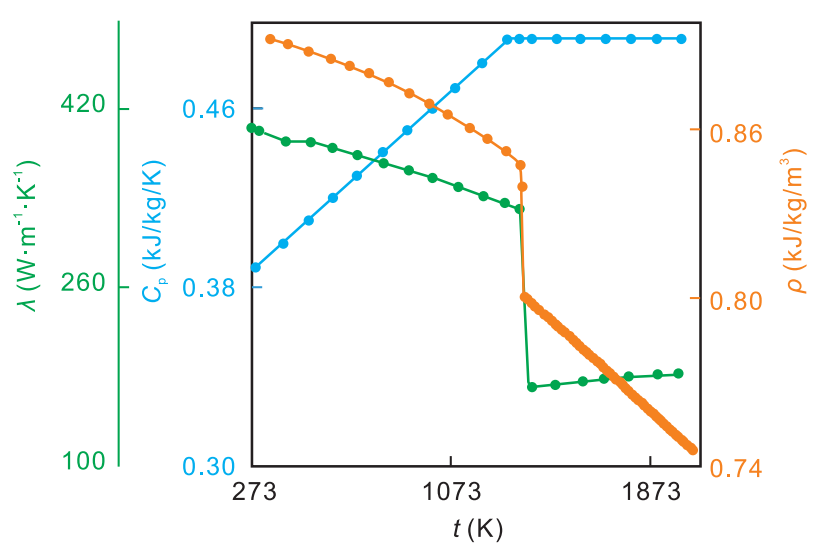

Fig. 4: Specific heat curve, thermal conductivity curve and density curve of $\mathrm{Cu}$

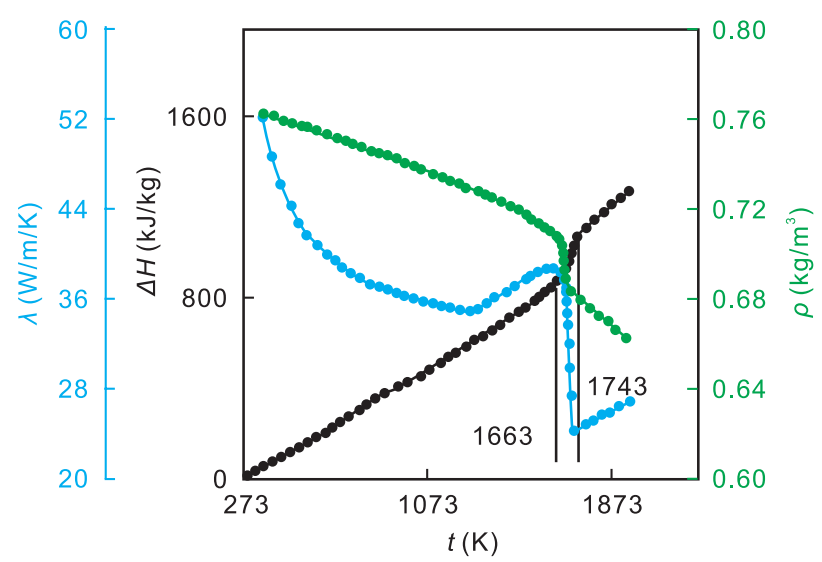

Fig. 5: Enthalpy curve, thermal conductivity curve and density curve of CF3 
Table 2: Parameters used in simulation

\begin{tabular}{|c|c|c|c|c|c|}
\hline Parameter & Cu plate & CF3 & Liquid slag & Once slag shell & Twice slag shel \\
\hline Density $\left(\mathrm{kg} / \mathrm{m}^{3}\right)$ & Fig. 4 & Fig. 5 & 2,700 & 2,700 & 2,700 \\
\hline Elasticity modulus (Max) $\left(\mathrm{N} / \mathrm{m}^{2}\right)$ & $1.1 \times 10^{1}$ & $2.1 \times 10^{11}$ & - & $7.7 \times 10^{10}$ & $7.7 \times 10^{10}$ \\
\hline Tangent modulus (Max) $\left(\mathrm{N} / \mathrm{m}^{2}\right)$ & $4.8 \times 10^{10}$ & $7.9 \times 10^{10}$ & - & $3.2 \times 10^{9}$ & $3.2 \times 10^{9}$ \\
\hline Plastic Poisson's ratio & 0.337 & 0.28 & - & 0.32 & 0.32 \\
\hline Elastic Poisson's ratio & 0.5 & 0.5 & - & 0.5 & 0.5 \\
\hline Tensile strength $(\mathrm{Pa})$ & $2.2 \times 10^{8}$ & $6.0 \times 10^{8}$ & - & $1 \times 10^{7}$ & $2.5 \times 10^{7}$ \\
\hline Yield strength $(\mathrm{Pa})$ & $6.5 \times 10^{7}$ & $4.5 \times 10^{8}$ & - & - & - \\
\hline Expansion coefficient ${ }^{[9-14]}$ & $1.8 \times 10^{-5}$ & $9 \times 10^{-6}$ & - & $10^{-7}$ & $10^{-7}$ \\
\hline Resistivity ${ }^{[9-11]}(\Omega \cdot m)$ & $1.7 \times 10^{-8}$ & $7.3 \times 10^{-7}$ & $3.34 \mathrm{e}-3$ & $4 \times 10^{-1}$ & $4 \times 10^{-1}$ \\
\hline Liquidus temperature $\left({ }^{\circ} \mathrm{C}\right)$ & - & 1470 & - & - & - \\
\hline Solid phase temperature $\left({ }^{\circ} \mathrm{C}\right)$ & 1,080 & 1,390 & 1,270 & 1,270 & 1,270 \\
\hline Thermal conductivity $(\mathrm{W} / \mathrm{m} / \mathrm{K})$ & Fig. 4 & Fig. 5 & 2.93 & 2.09 & 2.09 \\
\hline Specific heat $(\mathrm{kJ} / \mathrm{K} / \mathrm{kg})$ & Fig. 4 & Fig. 5 & 1.7 & 1.7 & 1.7 \\
\hline
\end{tabular}

\subsection{ESC up-pulling process}

Figure 6 shows the schematic of the ESC up-pulling process. The ESC starting process [Fig. 6(a)] is the first process of ESC, during which the slag is remelted gradually. The ESC uppulling process starts after the starting process, in which the metal is remelted gradually.

The EUPIM can be implemented at different initial uppulling moments after the starting process. At the suitable initial up-pulling moment, the inner mold up-pulling control inequality [Eq. (6) or (7)] satisfies the $L^{\prime}$ fluctuates in a small range from beginning to the end.

$$
\begin{gathered}
L \leqslant L^{\prime} \leqslant L+l \\
h+H_{\text {slag }}+d \leqslant L^{\prime} \leqslant h+H_{\text {slag }}+d+l
\end{gathered}
$$

In this study, $l$ is the once time up-pulling distance, $h$ is changed three times by changing $\tau: \tau_{1}, \tau_{2}, \tau_{3}$.

\section{Results and discussion}

\subsection{Deformation and stress of inner mold and slag shell before applying up-pulling force}

\subsubsection{Radial deformation of inner mold copper plate}

In this study, the base line is the slag-metal interface at $60 \mathrm{~s}$ after the ESC starting process. The once slag shell forms between the slag pool and the mold, and the twice slag shell forms when the temperature at the slag shell and slag-metal interface is higher than the melting point of slag ${ }^{[9]}$. Figure 7 shows the temperature field for EUPIM at 0-360 s after the ESC starting process before up-pulling. The temperature of the inner mold near the slag-metal interface is between $185^{\circ} \mathrm{C}$ and $235^{\circ} \mathrm{C}$. At $60-120 \mathrm{~s}$ before uppulling, the temperature of the casting near the intersection of the slag shell and slag-metal interface is about $1,240{ }^{\circ} \mathrm{C}, 30^{\circ} \mathrm{C}$ lower than the melting point of ANF-6 slag, $1,270{ }^{\circ} \mathrm{C}^{[10]}$, so, it is hard to remelt the once slag shell to form the twice slag shell. At

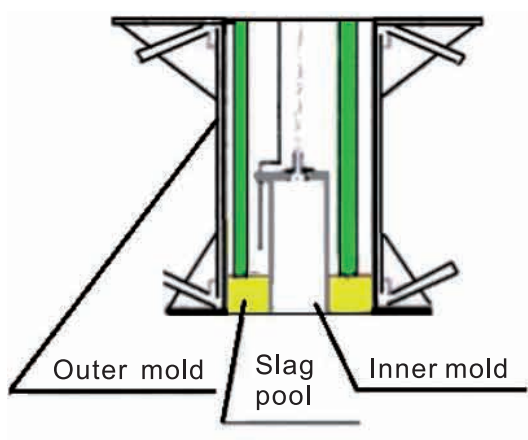

(a)

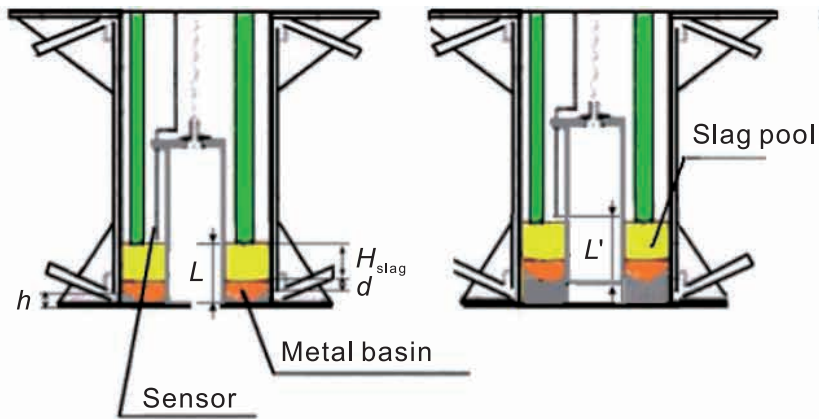

(b) (c)

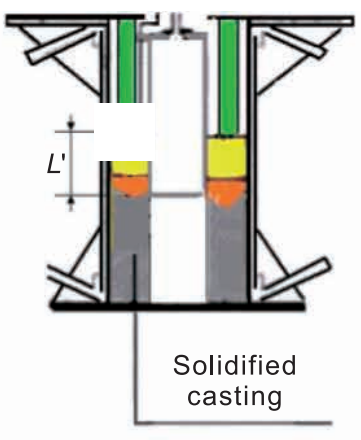

(d)

$\boldsymbol{H}_{\text {slag }}$ : height of slag; $\boldsymbol{d}$ : height of initial metal shell; $\boldsymbol{h}$ : height of initial solidified casting for ESC initial up-pulling moments; $L$ : distance from the slag-gas face to the bottom of the inner mold for the initial up-pulling; $L$ ': distance from the sensor to the bottom of the inner mold

Fig. 6: ESC up-pulling process schematic 


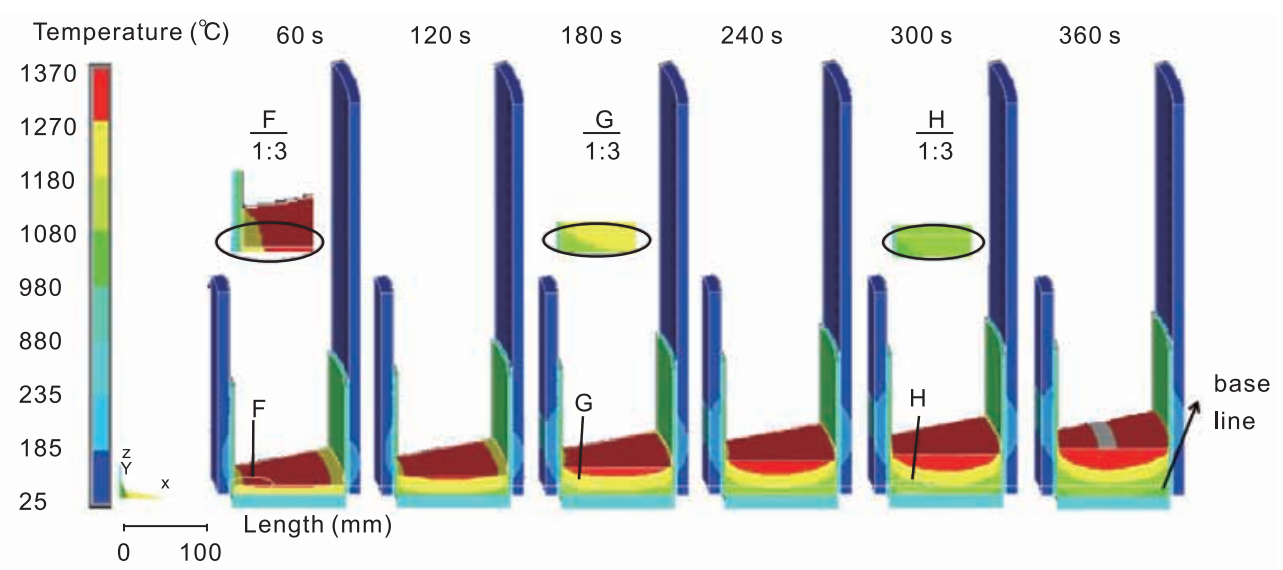

Fig. 7: EUPIM temperature field at $0-360 \mathrm{~s}$ after the starting process but before up-pulling

180-240 s and 300-360 s before up-pulling, the temperatures of the intersection of the slag shell and the slag-metal interface are about $1,290{ }^{\circ} \mathrm{C}$ and $1,320{ }^{\circ} \mathrm{C}$, about $20^{\circ} \mathrm{C}$ and $50{ }^{\circ} \mathrm{C}$ higher than the melting point of slag, so the once slag shell can be remelted to form the twice slag shell.
Figure 8 shows that the deformation of the inner mold copper plate near the base line increases gradually at 0-360 $\mathrm{s}$ before up-pulling. Areas I, J, K in Fig. 8 show the radial deformation field near the base line at different moments.

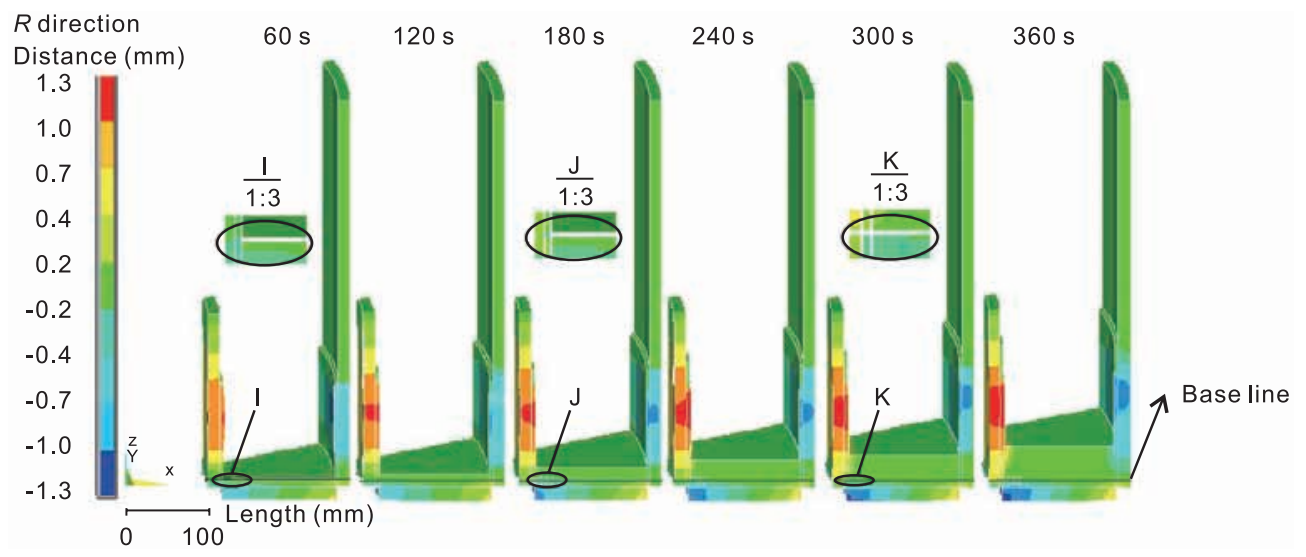

Fig. 8: EUPIM radial deformation at $0-360 \mathrm{~s}$ after the starting process before up-pulling

At $60-120 \mathrm{~s}, 180-240 \mathrm{~s}$ and $300-360 \mathrm{~s}$ before up-pulling, the average temperature of the semi-solidified metal near the base line decreases from about $1,370{ }^{\circ} \mathrm{C}$ to $1,270{ }^{\circ} \mathrm{C}, 1,270{ }^{\circ} \mathrm{C}$ to $1,180{ }^{\circ} \mathrm{C}$ and $1,180{ }^{\circ} \mathrm{C}$ to $1,080{ }^{\circ} \mathrm{C}$, respectively (Fig. 7). FEM analysis shows that the maximum radial deformation of the mold is $0.7 \mathrm{~mm}, 1.0 \mathrm{~mm}$ and $1.3 \mathrm{~mm}$, respectively, and the one at the base line is $0.2 \mathrm{~mm}, 0.4 \mathrm{~mm}$ and $0.6 \mathrm{~mm}$, respectively. The longer the solidification time on the base line, the tighter between the casting and the inner mold, and the bigger the radial deformation of the mold on the base line (from $0.2 \mathrm{~mm}$ to $0.6 \mathrm{~mm}$ ).

\subsubsection{Internal stress analysis}

Figure 9 shows the axial deformation field near the base line at different moments. It is found that, before applying the uppulling force, the maximum axial and radial internal stresses of the inner mold copper plate and the axial internal stress of the slag shell near the slag-metal interface increase gradually at $0-360 \mathrm{~s}$ after the starting process. At $60 \mathrm{~s}$ before up-pulling, both the maximum axial and radial internal stresses of the inner mold copper plate near the slag-metal interface are about $2 \times 10^{7} \mathrm{~Pa}$, which are smaller than the yield strength of copper plate $\left(6 \times 10^{7} \mathrm{~Pa}\right)$, so the deformation of the copper plate can be recovered by itself rapidly. When introducing the initial uppulling at about $60 \mathrm{~s}$ after the starting process, the axial internal stress of the slag shell is about $1.5 \times 10^{7} \mathrm{~Pa}$, which is greater than the tensile strength of the once slag shell $\left(1 \times 10^{7} \mathrm{~Pa}\right)$, which will easily cause tearing and leakage of the once slag shell.

At $180 \mathrm{~s}$ before up-pulling, the maximum axial and radial internal stresses of the inner mold copper plate near the slagmetal interface are about $3 \times 10^{7} \mathrm{~Pa}$, which are also less than the yield strength of the copper plate, so the deformation of the copper plate can be recovered by itself. When introducing the initial up-pulling at about $180 \mathrm{~s}$ after the starting process, the axial internal stress of the slag shell is about $2.0 \times 10^{7} \mathrm{~Pa}$, which is less than the axial tensile strength of the twice slag shell $\left(2.5 \times 10^{7} \mathrm{~Pa}\right)$. It is appropriate to start the initial up-pulling.

At $300 \mathrm{~s}$ before up-pulling, the maximum axial and radial internal stresses of the inner mold copper plate near the slagmetal interface are about $6 \times 10^{7} \mathrm{~Pa}$, similar to the yield strength 


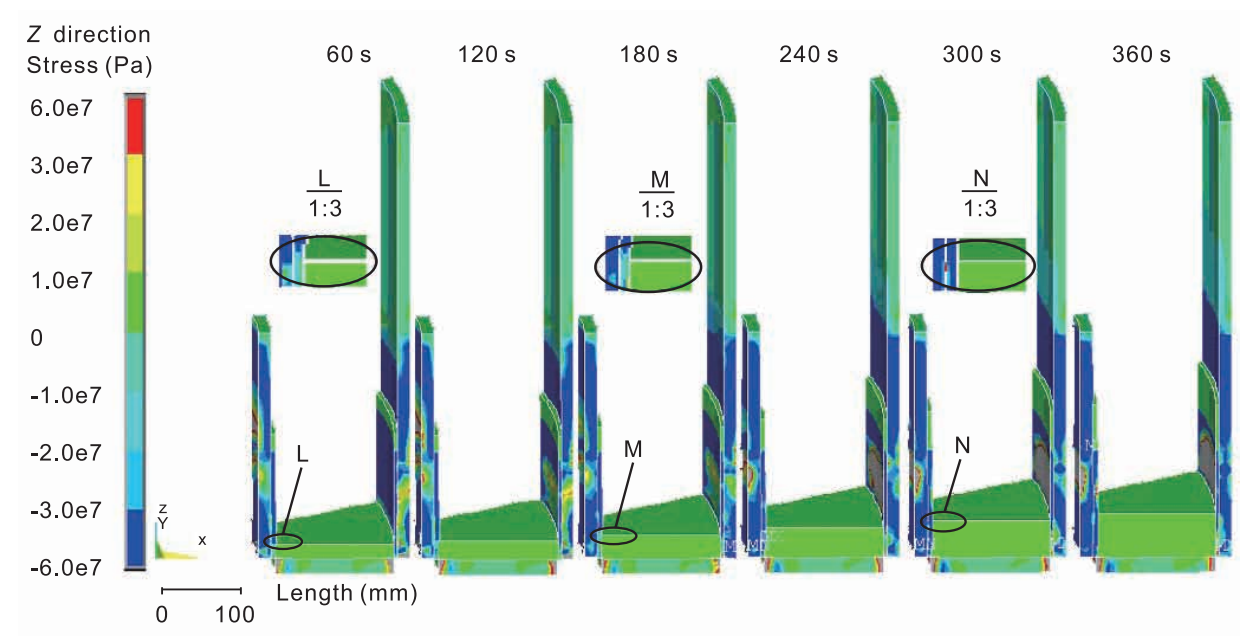

Fig. 9: EUPIM axial internal stress at $0-360 \mathrm{~s}$ after starting process before up-pulling

of copper plate, so the deformation of copper plate cannot be recovered by itself. When introducing the initial up-pulling at about $300 \mathrm{~s}$ after the starting process, the axial internal stress of the slag shell is about $3 \times 10^{7} \mathrm{~Pa}$, which is similar to the axial tensile strength of the twice slag shell. Therefore, it is inappropriate to carry out the initial up-pulling at this time.

Figure 10 shows the radial deformation field near the base line at different moments. It can be found that the maximum radial internal stress of the inner mold copper plate near the slag-metal interface shows the same changing tendency as that of the axial internal stress.

The test results of the axial internal stress of the inner mold copper plate near the slag-metal interface at $60 \mathrm{~s}, 180 \mathrm{~s}, 300 \mathrm{~s}$ after the starting process are $1.9 \times 10^{7} \mathrm{~Pa}, 2.8 \times 10^{7} \mathrm{~Pa}$, and $5.7 \times 10^{7} \mathrm{~Pa}$, respectively; and the radial internal stress of the inner mold copper plate near the slag-metal interface are $1.9 \times 10^{7} \mathrm{~Pa}, 2.8 \times 10^{7} \mathrm{~Pa}$, and $5.9 \times 10^{7} \mathrm{~Pa}$, respectively, which proved the validity of FEM analysis.

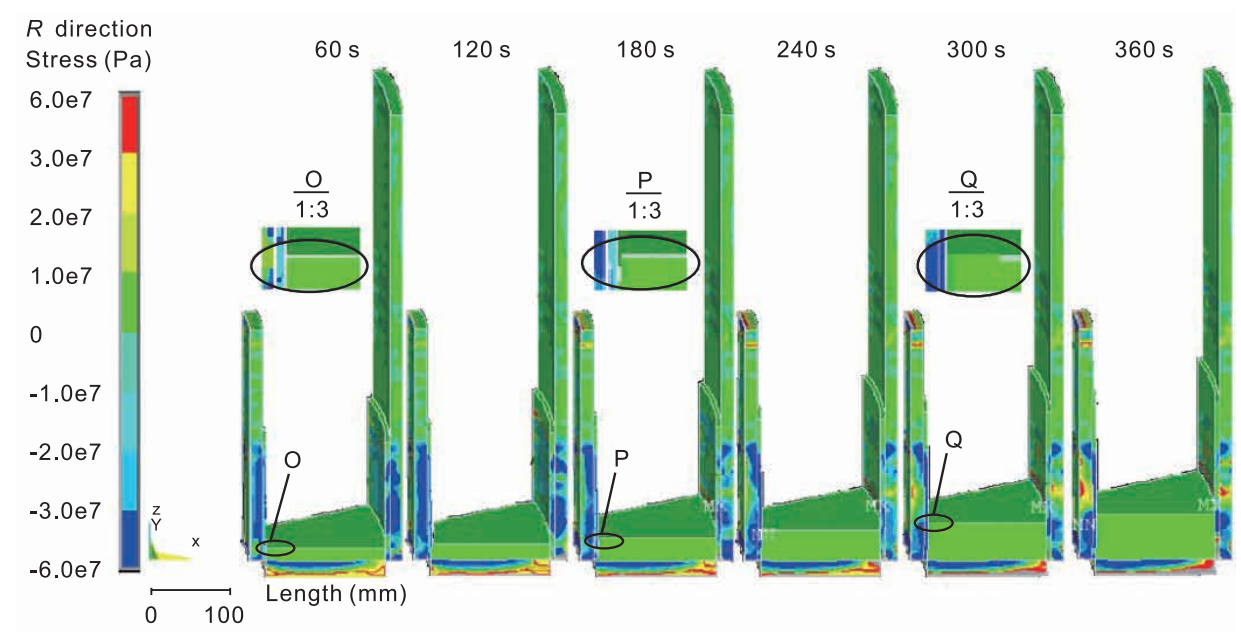

Fig. 10: EUPIM radial internal stress at $0-360 \mathrm{~s}$ after starting process before up-pulling

Therefore, according to the results and the discussion mentioned above, the suitable time for the initial up-pulling operation can be at about $180 \mathrm{~s}$ after the starting process. At this moment, the radial deformation, the axial and radial internal stresses of the inner mold copper plate and the axial internal stress of the slag shell near the slag-metal interface have the same increasing and decreasing tendency.

\subsection{Deformation and stress of inner mold and slag shell after applying up-pulling force}

\subsubsection{Radial deformation of inner mold copper plate}

Figure 11 shows the radial deformation of the inner mold copper plate (S1) and the deformation at the base line (S6) at 180-198 $\mathrm{s}$ after initial up-pulling. It can be seen that the maximum radial deformation of the inner mold copper plate near the slag-metal interface is about $0.3 \mathrm{~mm}$ and the one at the base line is about 0.2 $\mathrm{mm}$, which is decreased compared with the case of without uppulling force.

\subsubsection{Internal stress analysis.}

FEM analysis shows that at 180-198 s after up-pulling, the maximum axial and radial internal stresses of the inner mold copper plate and the maximum axial internal stress of the slag shell near the slag-metal interface increase gradually (Figs. 12-13). Areas W1 and W6 in Fig. 12 show the axial internal stresses of the inner mold copper plate and the slag shell at the 


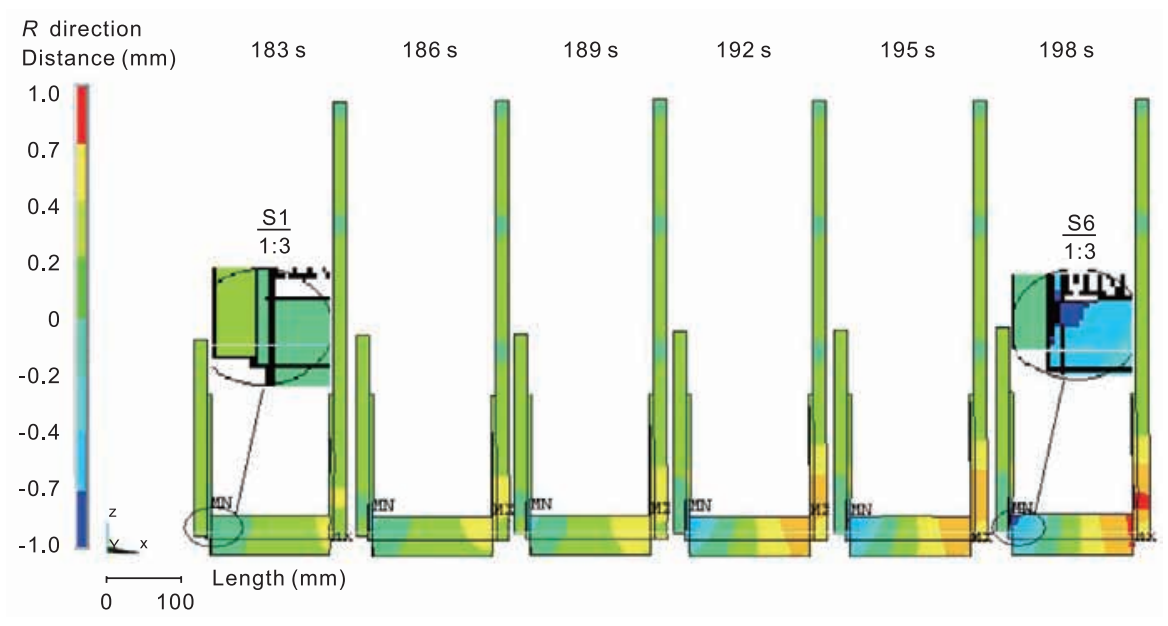

Fig. 11: EUPIM radial deformation at 180-198 s after up-pulling

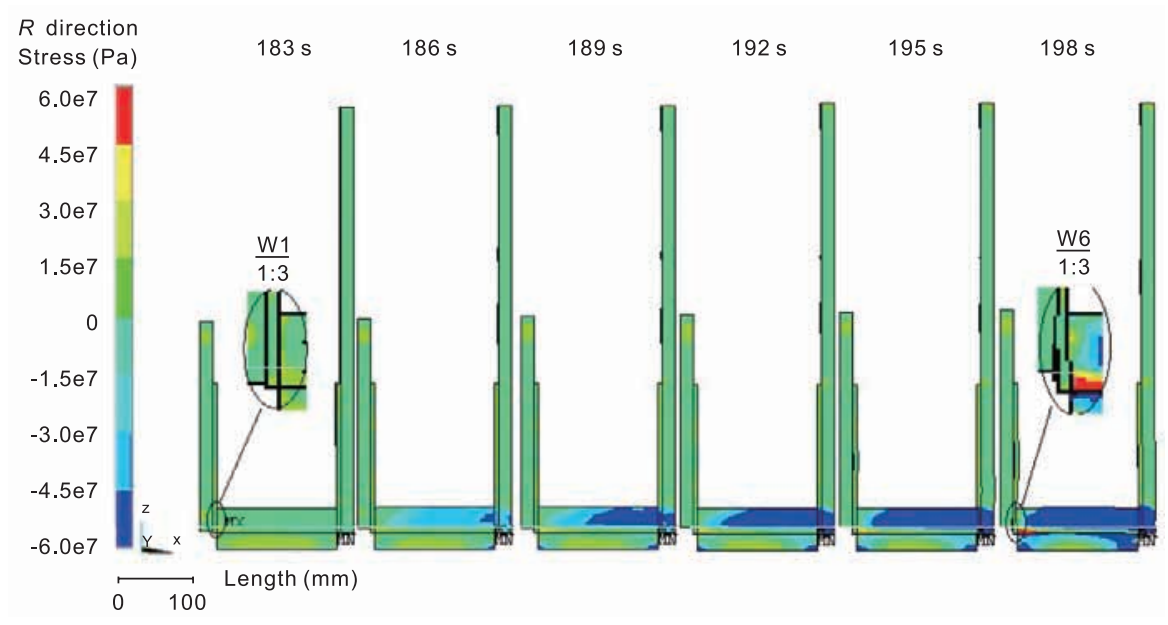

Fig. 12: EUPIM radial internal stress at $180-198 \mathrm{~s}$ after the starting process after up-pulling

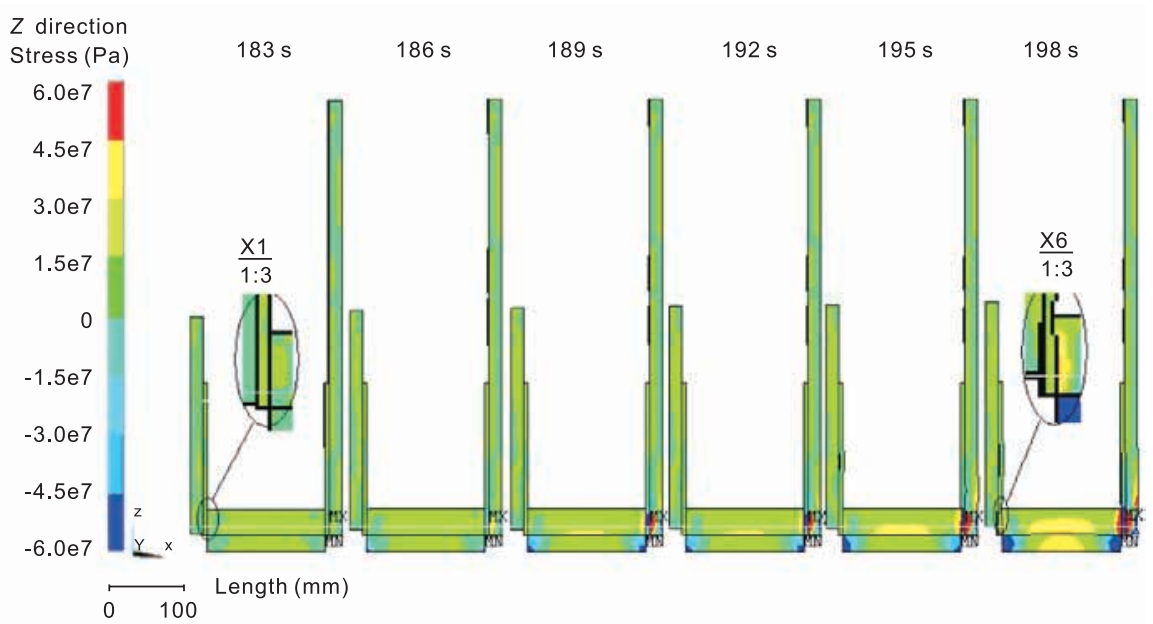

Fig. 13: EUPIM axial internal stress at 180-198 s after the starting process after up-pulling

base line for different times.

At 180-198 s after up-pulling, as shown in Fig. 12 and Fig. 13, both the maximum axial and radial internal stresses of the inner mold copper plate at the base line are $2.5 \times 10^{7} \mathrm{~Pa}$. The axial internal stress of the slag shell at the base line is about $2.2 \times 10^{7} \mathrm{~Pa}$. Areas X1 and X6 in Fig. 13 show the radial internal stresses of the inner mold copper plate and the slag shell at the base line for different times.

It can be seen that at 180-198 s, compared with the cases before up-pulling, the axial and radial internal stresses of the inner mold decrease, and the axial internal stress of the slag shell and the internal stress of the metal increase. 


\subsection{EUPIM casting experiment}

Finally, the qualified $\Phi 550 / \Phi 220$ ESC hollow cylindrical casting, as shown in Fig. 14, was manufactured by EUPIM at the suitable initial up-pulling moments (180-198 s).

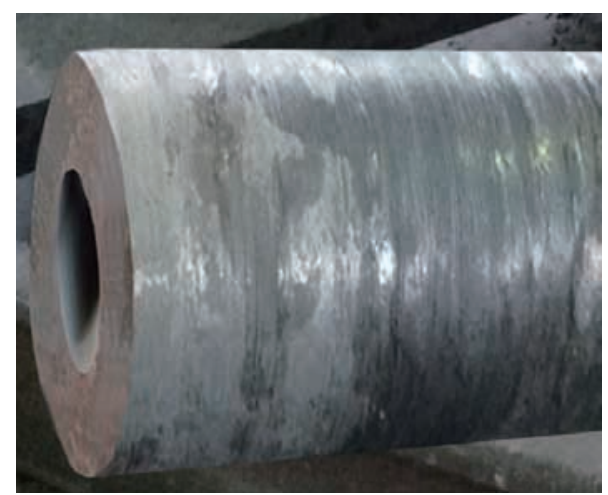

Fig. 14: $\$ 550 / \Phi 220$ ESC hollow cylindrical casting manufactured by EUPIM

\section{Conclusions}

The ESC up-pulling inner mold method (EUPIM) was used to produce hollow cylindrical castings with the multiple consumable electrodes. The radial deformation, the axial and radial internal stresses of the inner mold, and the axial internal stress of the slag shell were analyzed using the finite element method (FEM). The following conclusions can be drawn:

(1) The up-pulling control model is " $h+H_{\text {slag }}+d \leqslant L^{\prime} \leqslant h$ $+H_{\text {slag }}+d+l$ ". The FEM simulation results show that before applying the ESC up-pulling force, the twice slag shell forms at about $180 \mathrm{~s}$ after the ESC starting process because the temperature of the metal near the slag-metal interface can remelt the once slag shell.

(2) At 180-198 s after applying the ESC up-pulling force, the radial deformation of the inner mold at the base line is $0.2 \mathrm{~mm}$, both the maximum axial and radial internal stresses of the inner mold are $2.5 \times 10^{7} \mathrm{~Pa}$, and the axial internal stress of the slag shell at the base line is about $2.2 \times 10^{7} \mathrm{~Pa}$.

(3) In the present work, the suitable initial up-pulling moment is at about 180-198 s after the ESC starting process. Finally, the ESC hollow cylndrical casting $(\Phi 550 / \Phi 220)$ was produced by EUPIM at an initial up-pulling moment of $180 \mathrm{~s}$.

\section{Acknowledgemets}

This work was financially supported by the National Natural Science Foundation of China (Nos: 51674070, U1560203, 51434004, 51475313) and the Fundamental Research Funds for the Central Universities, China (Grant no.: N162504006).

\section{References}

[1] Medovar L B, Tsykulenko A K, Saenko V Ya, et al. New Electro slag technologies. In: Proc. Medovar Memorial Symposium. E. O. Palon Electric Welding Institute, 2001: 49-60.

[2] Dong $Y$ W, Zheng L C, Jiang $Z$ H. Mathematical modeling of producing hollow ingot by electroslag casting with liquid metal. Ironmaking and Steelmaking, 2013, 40(2):153-158. (In Chinese)

[3] Chen X C, Feng D, Fu J, et al. Recent development of electroslag-metallurgy. Journal of Iron and Steel Research, 2003, 15(2): 62-67. (In Chinese)

[4] Klein H J, Venal W V, Love K L. Production of electroslag remelted hollow ingots. Superalloys: Metallurgy and Manufacture. TMSAIME, Seven Springs, PA, 1976: 55-66.

[5] Paton B E, Medobar B I, Boikoi G A. Electroslag smelting of profiled castings. Special Electrometallurgy, 1971, 2: 632-633.

[6] Fedorovskii B, Medovar L, Stovpchenko G, et al. ESR of hollow ingots: new approaches to a traditional problem. In: Proceedings of 2011 Liquid Metal Processing \& Casting, Nancy, 2011: 97-107.

[7] Park J K, Samarasekera I V, Thomas B G, et al. Analysis formal and mechanical behavior of copper mould during thin slab casting. In: Proc. 3rd Steelmaking Conference, Warrendale P A: Iron and Steel Society, 2000: 9-21.

[8] Wang A G, Zhang T A, Dou Z H. ANSYS finite element analysis for thermoelectric field for slag pool for ESRC course. Chinese Journal of Process Engineering, 2006, 6 (S1): 105-109. (In Chinese)

[9] Krane M, Fahrmann J, Yanke E, et al. A comparison of predictions of transport phenomena in electroslag remelting to industrial data. In: Proc. 2011 International Symposium on Liquid Metal Processing \& Casting, Nancy, 2011:65-72.

[10] Jiang Z H. ESRC Metallurgy Physical Chemistry and Transmission Phenomenon. Northeast University Publishing House, Shenyang, China, 2000. (In Chinese)

[11] Kharicha A, Schutenhoer W, Ludwig A, et al. Numerical and experimental investigations on the ESR process of the hot work tool steel H11. In: Proc. 2009 International Symposium on Liquid Metal Processing \& Casting. Santa Fe, New Mexico, 2009: 227-228.

[12] Xiao K J. Analysis on reasons for explosion of crystallizer of ESRC. Special Steel Technology, 2006 (1): 41-42.

[13] Meug X, Zhu M Y. Mechanism of explaining liquid friction and flux consumption during non-sinusoidal oscillation in slab continuous casting mould. Canadian Metallurgical Quarterly, 2011, 50(1): 45-53.

[14] Fedorovskii B, Medovar L, Stovpchenko G, et al. ESR of hollow ingots: new approaches to a traditional problem. In: Proceedings for 2011 Liquid Metal Processing \& Casting, Nancy, 2011: 97-107. 